\title{
Jeden Tag eine Ladung Emotionen
}

\section{Eva Mell}

Stellvertretende Chefredaktorin der Schweizerischen Ärztezeitung

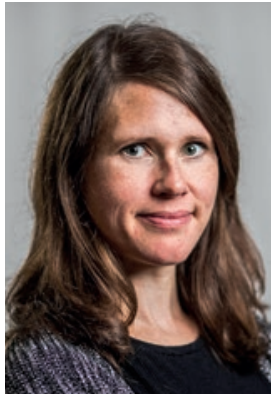

In meiner Familie lautet das Motto: Jeden Tag wird jede Emotion mindestens einmal durchlebt. Ich habe eine fünfjährige und eine zweijährige Tochter. Grösstmögliche Freude und tiefe Verzweiflung wechseln sich ebenso sehr ab wie Frust, Beleidigtsein, Trauer und Enttäuschung, aber auch Vergnügen, Liebe, Stolz oder Zufriedenheit. Wir Eltern stecken mittendrin im Gefühlsstrudel, müssen einerseits versuchen, uns nicht mitreissen zu lassen, und andererseits darauf achten, dass unser Nachwuchs das Wechselbad der Gefühle ohne Verbrennungen übersteht.

Und das alles nach einem Arbeitstag, der auch nicht ohne Emotionen an uns vorbeigeht. Mal überwiegen im Job die Selbstzweifel, dann die Freude über das Erreichte. Und am Ende ist meistens keine Gelegenheit, die vielen Gefühle zu reflektieren. Nach einem langen Tag kann es sein, dass bei allen Beteiligten die Nerven blank liegen. Wer kennt das nicht? Wie aber damit umgehen und Gelassenheit lernen? Dem Zeitgeist entsprechend blicken viele Menschen nach Asien und versuchen sich in buddhistischen Meditationstechniken, um Stress zu reduzieren und ihre Emotionen in den Griff zu kriegen.

Mal überwiegen im Job die Selbstzweifel, dann die Freude über das Erreichte. Und am Ende ist keine Zeit, die vielen Gefühle zu reflektieren.

Ich muss meinen Blick nur bis nach Thun schweifen lassen. Ein dort praktizierender Kinder- und Jugendpsychiater hat nämlich eine Methode entwickelt, um sogenannte negative Emotionen aus einem neuen Blickwinkel zu betrachten und dadurch gelassener zu werden: die Hypnotische Gefühlsmeditation (HGM). Die Methode kombiniert Meditation, Selbsthypnose und Emotionsregulation und ist erstaunlich leicht anzuwenden: Abwechselnd konzentriert man sich auf eine Emotion und auf ein Bild vor dem inneren Auge, das die Emotion symbolisiert. Erst die Emotion, dann das Bild, dann die Emotion, wieder das Bild und so weiter. In seinem Buch Badlands-Meditationen [1] beschreibt der Psychiater, der bis 2021 Supervisor und Ausbilder bei der Schweizerischen Ärztegesellschaft für Hypnose war und nun Mitglied des Vereins «hygs» ist, die Methode genauer: «Das Bedrohliche wird durch die konzentrierte Fokussierung auf Distanz gerückt, so dass ich es gut aushalte.» Das Resultat: Frust, Wut oder Verzweiflung erreichen mich nicht mehr in einer unaufhaltsamen Geschwindigkeit. Es wird möglich, sie fokussiert aus verschiedenen Blickwinkeln zu betrachten, um zu erkennen, warum sie tatsächlich da sind. Denn mit negativen Emotionen sei es wie mit Atomen,

Jede negative Emotion hat ihre Berechtigung. Sie zu reflektieren und einzuordnen und sich mit ihr anzufreunden ist anstrengend.

heisst es im Buch. Sie haben eine negative äussere Ladung, aber einen positiven Kern. Und es stimmt. Der Frust zeigt mir, was ich erreichen will, die Trauer, was mir wirklich lieb und wichtig ist.

Jede negative Emotion hat ihre Daseinsberechtigung und kann zu etwas Positivem führen. Sie zu reflektieren, ihren wahren Kern zu entdecken, sie einzuordnen und sich letztlich mit ihr anzufreunden ist eine Lebensaufgabe, die durchaus anstrengend sein kann. Das sehe ich bei meinen Kindern genau wie bei mir. In den herausforderndsten Phasen hat mir die Hypnotische Gefühlsmeditation Gelassenheit geschenkt.

Der Autor hat übrigens einen YouTube-Kanal, auf dem man diese Meditationsmethode in geführten und nach Emotionen sortierten Sessions ausprobieren kann [2]. Wie immer im Leben ist erst einmal etwas Überwindung gefragt. 20 Minuten dauern die Videos im Schnitt. Währenddessen benötigt man Ruhe und die Bereitschaft, sich auf etwas Neues einzulassen. Dass man nach kurzer Zeit keine Wunder erwarten darf, ist auch klar. Zur erfolgreichen Umsetzung der Methode brauche es Disziplin und Durchhaltewillen, warnt der Psychiater. Aber auch an dieser Stelle lohnt sich Gelassenheit. Wir alle haben jeden Tag die Gelegenheit zum Üben. Ob wir wollen oder nicht. Die Emotionen kommen sowieso.

\section{Literatur}

1 www.hypnose-hgm.com/publikationen/

2 www.youtube.com/channel/UCoeHKFKmGPxuBuRkj-wMXwQ 